\title{
Preparation and Characterization of Gliclazide Incorporated Cellulosic Microspheres: Studies on Drug Release, Compatibility and Micromeritics
}

\author{
Navid J ubaer Ayon ${ }^{1}$, Ikramul Hasan ${ }^{2}$, Md. Shfiqul Islam ${ }^{3}$ and Md. Selim Reza ${ }^{1}$ \\ ${ }^{1}$ Department of Pharmaceutical Technology, University of Dhaka, Dhaka-1000, Bangladesh \\ ${ }^{2}$ Department of Pharmacy, University of Asia Pacific, Dhanmondi, Dhaka-1209, Bangladesh \\ ${ }^{3}$ Department of Statistics, Biostatistics and Informatics, University of Dhaka, Dhaka-1000, Bangladesh
}

Received: May 07, 2014; Accepted: August 18, 2014; Published (web): October 13, 2014

\begin{abstract}
Polymeric microspheres of gliclazide were prepared to provide sustained release delivery of gliclazide to aid in continuous therapy with high margin of safety. Gliclazide was microencapsulated with different polymers namely HPMC K100LV, Ethocel (20 cps) and HPMC K100M by emulsion solvent evaporation technique using acetone as internal phase and liquid paraffin as external phase. Seventeen formulations were prepared using different drug loading and polymeric ratio of which nine formulations were prepared by a $3^{2}$ full factorial design. Each formulation was evaluated for flow properties, particle size, surface morphology, drug entrapment efficiency, drug release and compatibility. Yield (\%) for every batch of microspheres was measured. Flow properties of the microspheres were examined by determining bulk density, tapped density, Carr's compressibility index, Hausner ratio and angle of repose. Particle size distribution was examined by sieving and particle size analyzer. Surface morphology was determined by scanning electron microscopy (SEM). In-vitro drug release was studied in a paddle type dissolution apparatus (USP Type II Dissolution Apparatus) for a period of 8 hours at $37^{\circ} \mathrm{C}$ using phosphate buffer ( $\mathrm{pH}$ 7.4). FTIR and DSC studies established compatibility of the drug with the polymers. Microspheres prepared with Ethocel $(20 \mathrm{cps}$ ) and HPMC K100M were free flowing than those prepared only with HPMC K100LV. Entrapment efficiencies were within 75.88-99.69\%. Microspheres prepared with Ethocel (20 cps) and HPMC K100M showed more sustained release when compared to microspheres prepared with HPMC K100LV only. Increase in drug loading resulted in increased drug release for the microspheres. Kinetic modeling of in vitro dissolution profiles revealed the drug release mechanism ranging from diffusion controlled to anomalous type. Ethocel and HPMC $\mathrm{K} 100 \mathrm{M}$ in a ratio of 1:3 exhibited better sustained release properties than 1:1 and 3:1 ratios. The release rate of gliclazide from microspheres prepared with Ethocel $(20 \mathrm{cps})$ and HPMC K100M was less than the release rate of gliclazide from microspheres prepared with HPMC K100LV, demonstrating Ethocel and HPMC K100M as suitable polymeric blend for preparing the controlled release formulation for gliclazide whereas, HPMC K100LV was found not suitable candidate when used alone as a polymer.
\end{abstract}

Key words: Emulsification-solvent evaporation, Gliclazide, Microsphere, HPMC K100LV, Ethocel, HPMC K100M

\section{INTRODUCTION}

Microencapsulation is a useful method for prolonging drug release from dosage forms and reducing adverse effects. Recently, dosage forms that can precisely control the release rates and target drugs to a specific site have made an enormous impact on the formulation and development of novel drug delivery system. Microencapsulation is the coating of small solid particles, liquid droplets or gas

Correspondence to: Md. Selim Reza

Tel: +880-2-9677623; Fax: +880-9667222;

E-mail: selim.du@gmail.com

Dhaka Univ. J. Pharm. Sci. 13(2): 149-166, 2014 (December) bubbles with a thin film of coating or shell material that have an arbitrary particle size ranging between 1 and $1000 \mu \mathrm{m} .{ }^{1,2}$ So, microspheres are small spherical particles, typically ranging $1 \mu \mathrm{m}$ to $1000 \mu \mathrm{m}$ in diameters. They are sometimes referred to as micro particles. $^{3}$ These micro particles constitute an important part of the novel drug delivery system by virtue of their small size and efficient carrier characteristics.

Gliclazide is an oral antihyperglycemic agent used for the treatment of non-insulin dependent diabetes mellitus (NIDDM). It belongs to the 
sulfonylurea class of insulin secretagogues, which act by stimulating $\beta$ cells of the pancreas to release insulin. Gliclazide is a BCS Class II drug. It is rapidly absorbed from the GIT. It appears in the blood within 1-2 hrs. ${ }^{4}$ Like other drugs of BCS class II, reduction of particle size or increase in surface area will enhance its solubility. At present, patients have to take one or more doses of conventional or sustained release gliclazide tablets to maintain normal plasma glucose levels. Currently, gliclazide tablets available in the market have not yet attained the physiological goal of providing constant plasma glucose levels over an extended period of time to meet the basal needs between meals and during the night. Not only the less local gastric interferences but less chance of dose dumping make microencapsulation one of the best ways to provide sustain release of drug.

Among the cellulosic polymers, hydroxypropyl methylcellulose (HPMC) is one of the most important hydrophilic carrier materials which is used for the preparation of oral controlled drug delivery systems. ${ }^{5,6}$ HPMC is biodegradable and highly sweallable, which significantly influences the release kinetics of an incorporated drug. When the dosage form such as microsphere comes in contact with water or biological fluid the drug diffuses into the device, resulting in polymer chain relaxation with volume expansion ${ }^{7,8}$ and then the incorporated drug diffuses out of the system.

\section{MATERIALS AND METHODS}

Gliclazide and other excipients such as Methocel K100LV (Colorcon, India), Methocel K100M (Colorcon, India) and Ethocel $20 \mathrm{cps}$ (Colorcon, India) were obtained from ACI Pharmaceuticals Ltd. Acetone, n-hexane, Span 80, liquid paraffin, potassium dihydrogen phosphate, sodium hydroxide etc were procured from Merck (Germany).

Preparation of microspheres of gliclazide with cellulosic polymers by solvent evaporation technique. ${ }^{9}$ Polymeric microspheres of gliclazide were prepared according to non-aqueous emulsification solvent evaporation technique using three different cellulosic polymers HPMC K100LV, HPMC K100M and Ethocel $20 \mathrm{cps}$ all of which are insoluble in water; but can dissolve in mixture of organic solvents depending upon the ethoxy contents. Acetone was used as solvent and Span 80 was used as lipophilic surfactant for all the formulations. According to the formulation (Tables 1 and 2), the required amount of polymer was taken in $100 \mathrm{ml}$ glass beaker previously containing $10 \mathrm{ml}$ acetone. Then the mixture was thoroughly stirred until a clear solution of polymer was formed. The beaker was kept for microsphere preparation. $1 \mathrm{ml}$ of Span 80 was taken in properly washed and dried $1000 \mathrm{ml}$ plastic beaker. $100 \mathrm{ml}$ light liquid paraffin was added to Span 80 and the mixture was stirred at $1000 \mathrm{rpm}$ for 5 minutes. Then required amount of gliclazide powder was added to the respective formulation to form a suspension. Stirring was continued for 10 minutes. Then polymer solution was poured drop by drop into the drug suspension with simultaneous stirring. The stirring was continued until hard, uniform shaped microspheres were formed which required about 3 hours. The container was then kept static to allow the microspheres for settling down. Serial washing of microspheres was carried out with $n$-hexane. Then the microspheres were spread over a filter paper and left for drying in a desiccator for a day. The dried microspheres were kept in a vial with proper identification.

Formulation design. Seventeen batches of microspheres of gliclazide were prepared. Total amount of drug and polymer were kept constant at $2 \mathrm{~g}$ for each batch. First eight batches of microspheres were prepared using single polymer (HPMC K100LV) where the amount of drug was increased gradually keeping the total amount to $2 \mathrm{~g}$. The next nine batches were prepared with a combination of two polymers (Ethocel $20 \mathrm{cps}$ and HPMC K100M) according to a $3^{2}$ full factorial design where the drug loading and the polymeric ratios were considered as independent variables to evaluate their effect on other parameters which are considered as dependent variables. ${ }^{10}$ 
Table 1. Formulation of microspheres of gliclazide using single polymer (HPMC K100LV).

\begin{tabular}{ccc}
\hline Formulation No. (Batch size-2.0 g) & Drug : Gliclazide (g) & Polymer : HPMC K100LV (g) \\
\hline GH 1 (10\% Drug + 90\% Polymer) & 0.2 & 1.8 \\
GH 2 (20\% Drug + 80\% Polymer) & 0.6 & 1.4 \\
GH 3 (30\% Drug + 70\% Polymer) & 0.8 & 1.2 \\
GH 4 (40\% Drug + 60\% Polymer) & 1.0 & 1.0 \\
GH 5 (50\% Drug + 50\% Polymer) & 1.2 & 0.8 \\
GH 6 (60\% Drug+ 40\% Polymer) & 1.4 & 0.6 \\
GH 7 (70\% Drug + 30\% Polymer) & 1.6 & 0.4 \\
GH 8 (80\% Drug + 20\% Polymer) & 1.8 & 0.2 \\
\hline
\end{tabular}

Table 2. Formulation of microspheres of gliclazide by $3^{2}$ factorial design using combination of polymers (Ethocel 20 cps and HPMC K100M).

\begin{tabular}{|c|c|c|c|}
\hline \multirow{2}{*}{$\begin{array}{c}\text { Drug } \\
\text { Loading } \\
\downarrow\end{array}$} & \multicolumn{3}{|c|}{ Polymer (Cellulose) } \\
\hline & $\begin{array}{l}\text { Ethocel-Methocel } \\
(1: 3)\end{array}$ & $\begin{array}{l}\text { Ethocel-Methocel } \\
(1: 1)\end{array}$ & $\begin{array}{c}\text { Ethocel-Methocel } \\
(3: 1)\end{array}$ \\
\hline & GC 11 & GC 21 & GC 31 \\
\hline $\begin{array}{c}30 \% \\
\text { (Ploymer-70\%) }\end{array}$ & $\begin{array}{l}(0.60 \mathrm{~g} \text { Gliclazide }+0.35 \mathrm{~g} \\
\text { Ethocel }+1.05 \mathrm{~g} \text { Methocel })\end{array}$ & $\begin{array}{c}(0.6 \mathrm{~g} \text { Gliclazide }+0.70 \mathrm{~g} \text { Ethocel } \\
+0.70 \mathrm{~g} \text { Methocel })\end{array}$ & $\begin{array}{l}(0.60 \mathrm{~g} \text { Gliclazide }+1.05 \mathrm{~g} \\
\text { Ethocel }+0.35 \mathrm{~g} \text { Methocel })\end{array}$ \\
\hline & GC 12 & GC 22 & GC 32 \\
\hline $\begin{array}{c}50 \% \\
\text { (Plovmer-50\%) }\end{array}$ & $\begin{array}{c}(1.0 \mathrm{~g} \text { Gliclazide }+0.25 \mathrm{~g} \text { Ethocel } \\
+0.75 \mathrm{~g} \text { Methocel })\end{array}$ & $\begin{array}{l}(1.0 \mathrm{~g} \text { Gliclazide }+0.50 \mathrm{~g} \\
\text { Ethocel }+0.50 \mathrm{~g} \text { Methocel })\end{array}$ & $\begin{array}{l}\text { (1.0g Gliclazide }+0.75 \mathrm{~g} \text { Ethocel } \\
+0.25 \mathrm{~g} \text { Methocel })\end{array}$ \\
\hline $\begin{array}{c}70 \% \\
\text { (Ploymer-30\%) }\end{array}$ & $\begin{array}{c}\text { GC 13 } \\
(1.4 \mathrm{~g} \text { Gliclazide }+0.15 \mathrm{~g} \text { Ethocel } \\
+0.45 \mathrm{~g} \text { Methocel })\end{array}$ & $\begin{array}{c}\text { GC 23 } \\
\begin{array}{c}(1.4 \mathrm{~g} \text { Gliclazide }+0.30 \mathrm{~g} \text { Ethocel } \\
+0.30 \mathrm{~g} \text { Methocel })\end{array}\end{array}$ & $\begin{array}{c}\text { GC } 33 \\
\begin{array}{c}(1.4 \mathrm{~g} \text { Gliclazide }+0.15 \mathrm{~g} \text { Ethocel } \\
+0.45 \mathrm{~g} \text { Methocel })\end{array}\end{array}$ \\
\hline
\end{tabular}

\section{In vitro characterization of polymeric microspheres of gliclazide}

Production yield. ${ }^{11}$ The yield (\%) was determined by dividing the weight of microspheres by weight of total amount used in the formulation, and multiplying it by 100 .

Yield $(\%)=\frac{\text { Wt of microspheres in gm }}{\text { Wt of total amount of materialsin gm }} \times 100$

Determination of drug entrapment efficiency. ${ }^{12}$ The drug entrapment efficiency was calculated by using the following equation-

Entrapmentefficieny $(\%)=\frac{\text { Calculated conc of drug }}{\text { Theoritical conc of drug }} \times 100$

Effect of drug loading and polymer ratio on drug entrapment efficiency was then analyzed by constructing complex line plot using gg Plot Software ( $\mathrm{R}$ i386.3.0.0) and response surface analysis using Design-Expert ${ }^{\circledR}$ software. Analysis of variance was also studied for determining the statistically important variables which have effects on drug entrapment efficiency.
Micromeritics study. ${ }^{13,14}$ Flow properties were studied by determining the Carr's compressibility index, Hausner ratio and angle of repose. Bulk density and tapped density were determined using a volumetric cylinder.

$$
\text { Bulk density }=\frac{\text { Wt of microspheres in gm }}{\text { Bulk volume of microspheres }}
$$

Tapped density is determined according to the following equation by tapping known amount of microspheres for 1 minute until it gave constant volume.

Tapped density $=\frac{\text { Wt of microspheres in gm }}{\text { Volume of microspheres after tapping }}$

Then, Carss's compressibility index and Hasuner ratio were determined using the following equations: Carr's compressibility index $(\%)=$

$$
\frac{\text { Tapped density - Bulk density }}{\text { Tapped density }} \times 100
$$


Hausner ratio $=\frac{\text { Tapped density }}{\text { Bulk density }} \times 100$

Angle of repose was calculated by fixed funnel method. Accurately weighed microspheres were passed through the funnel fixed on a stand with a white paper placed under it. The microspheres falling through the funnel on the paper formed a pile. Then the funnel was lowered in such a way so that the tip of the funnel touched the apex of the pile of the microspheres. Then the paper with the microspheres on it was removed, and the height from the base to the funnel was measured. The diameter of the pile of microspheres was measured several times, and the average value was taken as the diameter of the pile. From this the radius was calculated. Thus, angle of repose was calculated for all batches of microspheres using the following equation:

$$
\theta=\frac{\text { Height of the pile (inch) }}{\text { Radius of the power cone (degree) }} \times 100
$$

Here, $\theta=$ Angle of repose.

Particle size analysis. ${ }^{15,16}$ Particle sizes of the microspheres prepared with Ethocel and HPMC K100M combined was determined by laser diffracting particle size analyzer (Partica $\left.{ }^{\circledR} 5960\right)$. The analyzer provided the particle size according to the refractive index of that particle. The particle size distribution was represented as bar diagram as well as in numeric values.

Study of surface morphology by scanning electron microscopy (SEM). ${ }^{17,18}$ Scanning electron microscopy was used to study the morphology and surface topography of the microspheres. The samples were scanned using scanning electron microscope (s$3400 \mathrm{~N}$, Hitachi) under different magnification.

In vitro dissolution study of microspheres containing gliclazide. ${ }^{19,20}$ In vitro dissolution study was performed in a paddle type (Type II) dissolution apparatus. Weighed amount of microspheres containing $100 \mathrm{mg}$ drug was taken from each batch of formulation for dissolution purpose. Phosphate buffer of $\mathrm{pH} 7.4$ was used as dissolution media, paddle speed was set at $100 \mathrm{rpm}$ and temperature was maintained at $37^{\circ} \mathrm{C}$. The dissolution process was carried out for 8 hours and $10 \mathrm{ml}$ dissolution sample from each dissolution media was withdrawn at the end of $1^{\text {st }}$ hour, $2^{\text {nd }}$ hour, $3^{\text {rd }}$ hour, $4^{\text {th }}$ hour, $5^{\text {th }}$ hour, $6^{\text {th }}$ hour, $7^{\text {th }}$ hour and $8^{\text {th }}$ hour.

Then the amount of drug released and rate constants were analyzed using different mathematical models to evaluate the release mechanism to find the best fit by observing the $\mathrm{R}^{2}$ value. Korsmeyer-Peppas model was used to determine the ' $n$ ' value to make conclusion about the diffusion mechanism. Successive fractional dissolution time for each batch was also measured and analyzed by gg Plot software to observe the effect of drug loading and polymer ratio.

Compatibility studies of drug and polymer within gliclazide microspheres. ${ }^{21}$

Fourier transform infrared spectrophotometry (FTIR). The IR spectrum of the pure drug, pure polymers and optimized microsphere formulations were obtained to evaluate the chemical integrity and compatibility of the drug with the polymers in the microspheres.

Differential scanning calorimetery (DSC). DSC study was carried out to evaluate the interaction between the drug and the polymers in the microspheres by using a Differential Scanning Calorimeter (DSC 60, Shimadzu). The specific heat and enthalpies of transition were determined.

\section{RESULTS AND DISCUSSION}

Production yield (\%) of microspheres. For microspheres prepared with HPMC K100LV, there is a wide variation in the yield (\%) value, the lowest value being $76.70 \%$ for $\mathrm{GH} 1$ (10\% drug loading) and the highest one being $95.75 \%$ for GH6 (60\% drug loading). Microspheres prepared with Ethocel and HPMC K100M, the yield (\%) value exhibited lowest variation, with the minimum being $95.85 \%$ for $\mathrm{GC} 11$ (30\% drug loading) where the ratio of polymer (Ethocel: HPMC K100M) was 1:3 and the maximum being $100.15 \%$ for GC33 (70\% drug loading) where the ratio of polymer (Ethocel: HPMC K100M) was 3:1.

Drug entrapment efficiency. Figure 1 depicts the relationship between the drug entrapment efficiency and the drug loading. The bar diagram 
exhibits that, when only HPMC K100LV is used as a polymer, the drug entrapment efficiency is maximum for GH1 (10\% drug loading) and minimum for GH5 (50\% drug loading). The bar diagram also reveals another important fact that the drug entrapment efficiency becomes maximum $(97.71 \%)$ when the ratio of polymers (Ethocel: HPMC K100M) is 1:3 with $70 \%$ drug loading and minimum $(82.39 \%)$ when the ratio of polymers is $1: 1$ with $30 \%$ drug loading.
But irrespective of polymer ratios, the drug entrapment efficiency increases with the increase in the drug loading. So, it can be concluded that, microspheres prepared with HPMC K100M and Ethocel, HPMC K100M when used in its highest amount become more effective for obtaining better drug entrapment efficiency.

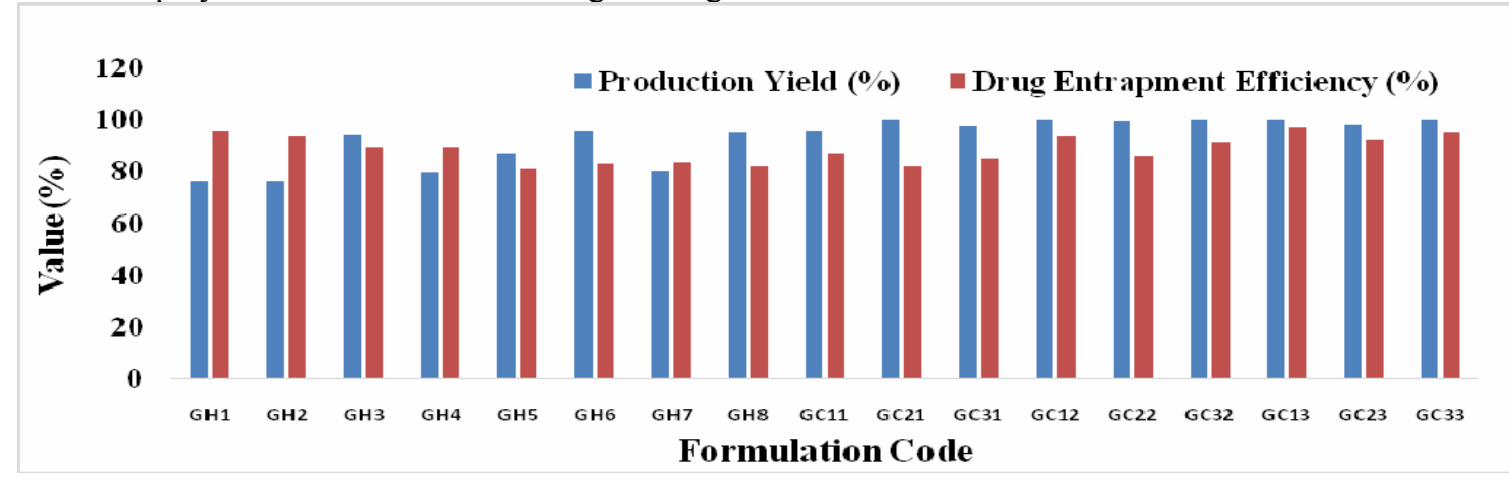

Figure 1. Production yield (\%) and drug entrapment efficiency of microspheres

Analysis of impact of drug loading and polymer ratio on drug entrapment efficiency using gg plot software (R i386.3.0.0). Figure 2 reveals that, for microspheres prepared with HPMC K100LV, drug entrapment efficiency decreases with increase in drug loading and decrease in percentages of polymer. For batches of microspheres prepared with Ethocel and HPMC K100M, drug entrapment efficiency increases with increase in drug loading and the maximum drug entrapment efficiency is obtained when Ethocel and HPMC K100M were used in 1:3 ratio for all three drug loadings $(30 \%, 50 \%$ and $70 \%)$, that is the batches of microspheres of GC11, GC21 and GC31 have the highest drug entrapment efficiency.

The model F-value of 117.31 implies that the model is significant. Values of "Prob $>$ F" less than 0.0500 indicate model terms are significant. In this case A, B, B2 are significant model terms. The "Lack of Fit F-value" of 1.68 implies that the Lack of Fit is not significant relative to the pure error. So, it can be can said that both drug loading and ratio of polymer have individualized effect on drug entrapment efficiency of various batches of microspheres prepared with Ethocel and HPMC K100M.

Table 3. Coding for gg plot for analyzing impact of drug loading and polymer on drug entrapment efficiency.

\begin{tabular}{lc}
\hline Parameter & Code \\
\hline Presence of polymer & 1 \\
Absence of polymer & 0 \\
Single polymer & $\mathrm{a}$ \\
Combination of polymer (1:3) & $\mathrm{b}$ \\
Combination of polymer (1:1) & $\mathrm{c}$ \\
Combination of polymer (3:1) & $\mathrm{d}$ \\
HPMC K100LV & 1 \\
HPMC K100M + Ethocel & 2 \\
\hline
\end{tabular}

Response surface plot (Figure 3) discloses the relationship of drug entrapment efficiency with drug loading and polymeric ratio. Increase in drug loading causes increase in drug entrapment efficiency in case of microspheres prepared with Ethocel and HPMC K100M. Increasing concentration of Ethocel results in decreased entrapment. It can also be concluded that, 1:1 ratio of Ethocel and HPMC K100M exhibits the poorest drug entrapment efficiency for all drug 
loadings, which can be clarified by a gradual fall up to ' 0 ' coded value and gradual rise from ' 0 ' coded value along $\mathrm{X} 2$ axis in figure 3 . Contour plot in figure 4 reveals the different drug loading and polymer ratios to achieve $85 \%, 90 \%$ and $95 \%$ drug entrapment efficiency.

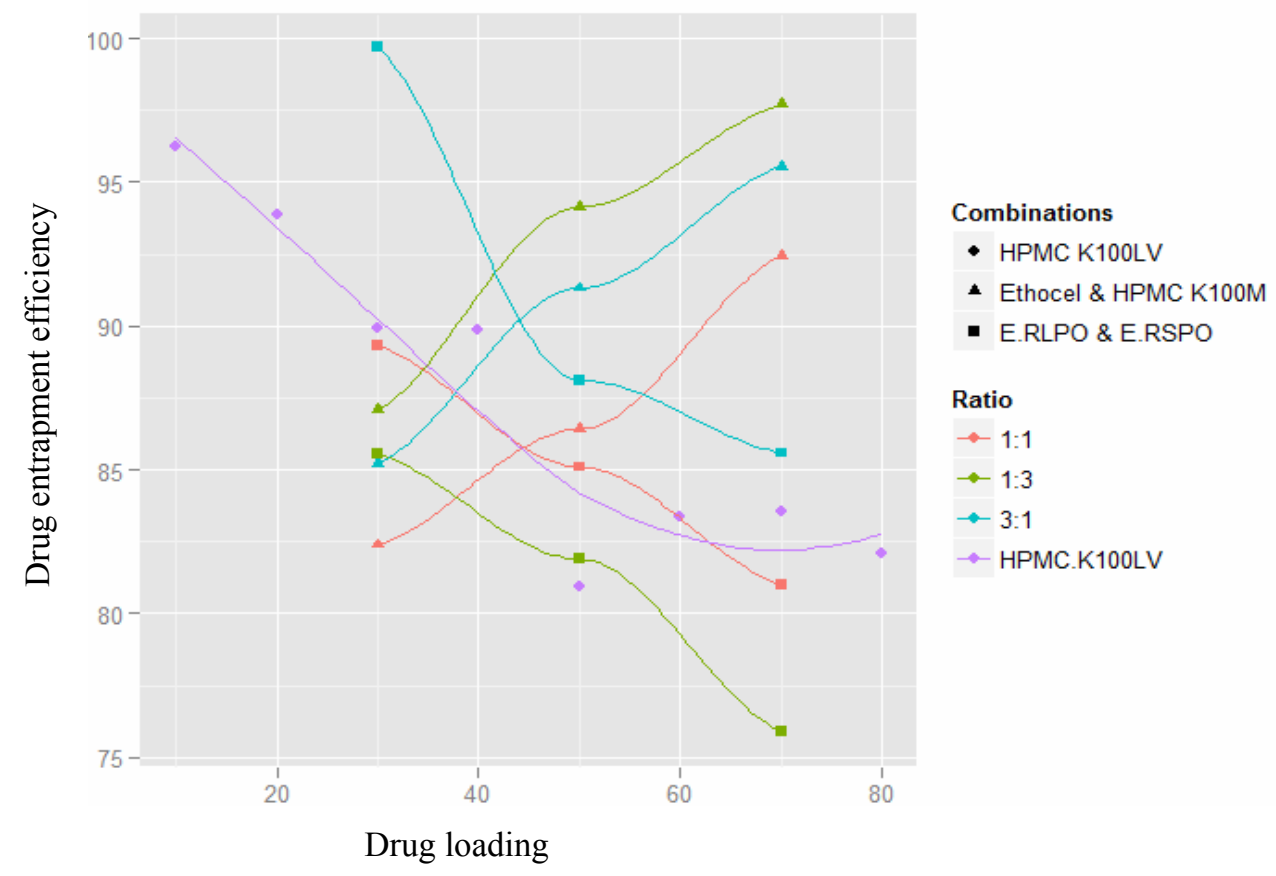

Figure 2. Complex line-plot effect of drug loading and polymer on drug entrapment efficiency.

\section{ANOVA (Analysis of variance) for response surface reduced quadratic model}

Table 4. ANOVA for drug entrapment efficiency of various batches.

\begin{tabular}{ccccccc}
\hline Source & Sum of squares & df & Mean square & F value & $\begin{array}{c}\text { P-value } \\
\text { Probe }>\text { F }\end{array}$ & \\
\hline $\begin{array}{c}\text { Model } \\
\text { A-Drug Loading }\end{array}$ & 0.011 & 3 & $3.631 \mathrm{E}-003$ & 117.31 & $<0.001$ & Significant \\
$\begin{array}{c}\text { (Gliclazide) } \\
\text { B-Ethocel:HPMC }\end{array}$ & $8.392 \mathrm{E}-003$ & 1 & $8.392 \mathrm{E}-003$ & 271.14 & $<0.001$ & \\
K100M & $4.090 \mathrm{E}-004$ & 1 & $4.090 \mathrm{E}-004$ & 13.21 & 0.0027 & \\
B $^{2}$ & $2.092 \mathrm{E}-003$ & 1 & $2.092 \mathrm{E}-003$ & 67.57 & $<0.0001$ & \\
Residual & $4.333 \mathrm{E}-004$ & 14 & $3.095 \mathrm{E}-005$ & & & \\
Lack of Fit & $2.028 \mathrm{E}-004$ & 5 & $4.057 \mathrm{E}-005$ & 1.68 & 0.2583 & \\
\hline
\end{tabular}

Micromeritics study. Particles having excellent flow properties will have value of Carr's Compressibility index, Hausner ratio and Angle of repose in the range of $\leq 10,1.00-1.11$ and 25-30, respectively. The results in Table 8 indicate that microspheres prepared with HPMC K100LV exhibits poor flow properties. Among the eight batches prepared with HPMC K100LV, the best flow properties were shown by GH4 (40\% drug loading) and the worst by GH3 (30\% drug loading) which requires aid to flow through the funnel. On the other hand, microspheres prepared with Ethocel and HPMC K100M exhibit improved flow properties. Best flow properties were exhibited by GC31 (30\% drug loading) and $\mathrm{GC} 13$ (70\% drug loading), whereas, the worst exhibited by GC11 (30\% drug 
loading). In GC31, the ratio of polymers (Ethocel: HPMC K100M) was 1:3 and in GC13, the ratio was 3:1 (Ethocel: HPMC K100M). So, it can be concluded that when Ethocel and HPMC K100M were used in combination in preparing microspheres, the higher is the amount of HPMC K100M better is the flow properties.

Table 5. Dependent and independent variables obtained from gliclazide microspheres.

\begin{tabular}{cccc}
\hline $\begin{array}{c}\text { Formulation } \\
\text { No. }\end{array}$ & \multicolumn{2}{c}{ Coded factor level } & Response \\
\cline { 2 - 4 } & Gliclazide & $\begin{array}{c}\text { Ethocel : } \\
\text { HPMC } \\
\text { K100M }\end{array}$ & $1 \mathrm{Y}$ \\
\cline { 2 - 4 } & & $\mathrm{B}$ & $\begin{array}{c}\text { Log of Drug } \\
\text { Entrapment } \\
\text { Efficiency }(\%)\end{array}$ \\
\cline { 2 - 4 } & & & 87.11 \\
2 & $30 \%$ & -1 & 85.53 \\
3 & $30 \%$ & -1 & 82.39 \\
4 & $30 \%$ & 0 & 80.50 \\
5 & $30 \%$ & 0 & 85.22 \\
6 & $30 \%$ & 1 & 82.70 \\
7 & $30 \%$ & 1 & 94.15 \\
8 & $50 \%$ & -1 & 93.02 \\
9 & $50 \%$ & -1 & 86.42 \\
10 & $50 \%$ & 0 & 85.47 \\
11 & $50 \%$ & 0 & 91.32 \\
12 & $50 \%$ & 1 & 90.38 \\
13 & $50 \%$ & 1 & 97.71 \\
14 & $70 \%$ & -1 & 96.77 \\
15 & $70 \%$ & -1 & 92.45 \\
16 & $70 \%$ & 0 & 91.64 \\
17 & $70 \%$ & 0 & 95.55 \\
\hline & $70 \%$ & 1 &
\end{tabular}

Table 6. Translation in actual unit of coded value.

\begin{tabular}{ccc}
\hline Factors & Actual units & Coded level \\
\hline Drug loading & $30 \%$ & $30 \%$ \\
(Gliclazide) & $50 \%$ & $50 \%$ \\
& $70 \%$ & $70 \%$ \\
Ethocel : HPMC & $1: 3$ & -1 \\
K100M & $1: 1$ & 0 \\
& $3: 1$ & 1 \\
\hline
\end{tabular}

Final equations in terms of coded factors.

$\log _{10}$ (Drug entrapment efficiency) $=+1.94+0.026$

$\times \mathrm{A}-5.838 \times 10^{-3} \times \mathrm{B}+0.023 \times \mathrm{B}^{2}$
Particle size analysis. As all the microspheres prepared with HPMC K100LV passed through the sieve number 20 and could not pass through sieve number 30 as described in materials and methods. So, it can be concluded that the particle size of the microspheres of batch number GH1, GH2, GH3, GH4, GH5, GH6, GH7, GH8 is in the range of 595$841 \mu \mathrm{m}$. Decreasing polymer concentration or increasing drug loading results in decrease in particle size for the microspheres which are prepared by Ethocel and HPMC K100M. For example GC11, $\mathrm{GC} 12$ and $\mathrm{GC} 13$ are microsphere batches prepared by using Ethocel and HPMC K100M having polymer loading of $70 \%, 50 \%$ and $30 \%$ have a mean size of $913.04 \mu \mathrm{m}, 677.02 \mu \mathrm{m}$ and $472.23 \mu \mathrm{m}$ respectively.

Table 7. Results of micromeritics study of microspheres.

\begin{tabular}{|c|c|c|c|c|c|}
\hline Formulation & $\begin{array}{c}\text { Bulk } \\
\text { density } \\
\left(\mathrm{P}_{\mathrm{B}}\right) \\
(\mathrm{g} / \mathrm{ml})\end{array}$ & $\begin{array}{c}\text { Tapped } \\
\text { density } \\
\left(\mathrm{P}_{\mathrm{T}}\right)(\mathrm{g} / \mathrm{ml})\end{array}$ & $\begin{array}{c}\text { Carr's } \\
\text { compressibility } \\
\text { index }\end{array}$ & $\begin{array}{l}\text { Hausner } \\
\text { ratio }\end{array}$ & $\begin{array}{c}\text { Angle } \\
\text { of } \\
\text { repose } \\
(\theta)\end{array}$ \\
\hline GH1 & 0.48 & 0.69 & 31.25 & 1.45 & $36.87^{\circ}$ \\
\hline GH2 & 0.26 & 0.40 & 36.67 & 1.58 & $53.13^{\circ}$ \\
\hline GH3 & 0.27 & 0.47 & 42.86 & 1.75 & $45.81^{\circ}$ \\
\hline GH4 & 0.38 & 0.54 & 28.57 & 1.4 & $48.81^{\circ}$ \\
\hline GH5 & 0.52 & 0.88 & 41.18 & 1.7 & $45.73^{\circ}$ \\
\hline GH6 & 0.32 & 0.50 & 36.67 & 1.58 & $26.57^{\circ}$ \\
\hline GH7 & 0.34 & 0.48 & 29.17 & 1.41 & $36.87^{\circ}$ \\
\hline GH8 & 0.38 & 0.56 & 32.00 & 1.47 & $21.80^{\circ}$ \\
\hline GC11 & 0.27 & 0.32 & 14.29 & 1.17 & $19.18^{\circ}$ \\
\hline $\mathrm{GC} 21$ & 0.39 & 0.43 & 8.00 & 1.09 & $22.83^{\circ}$ \\
\hline GC31 & 0.39 & 0.41 & 4.00 & 1.04 & $23.96^{\circ}$ \\
\hline $\mathrm{GC} 12$ & 0.31 & 0.33 & 6.25 & 1.07 & $21.80^{\circ}$ \\
\hline GC22 & 0.45 & 0.47 & 4.55 & 1.05 & $21.80^{\circ}$ \\
\hline GC32 & 0.44 & 0.46 & 4.35 & 1.05 & $21.80^{\circ}$ \\
\hline GC13 & 0.40 & 0.412 & 4.00 & 1.04 & $20.96^{\circ}$ \\
\hline GC23 & 0.49 & 0.52 & 5.00 & 1.052 & $19.80^{\circ}$ \\
\hline GC33 & 0.34 & 0.37 & 6.67 & 1.071 & $19.57^{\circ}$ \\
\hline
\end{tabular}



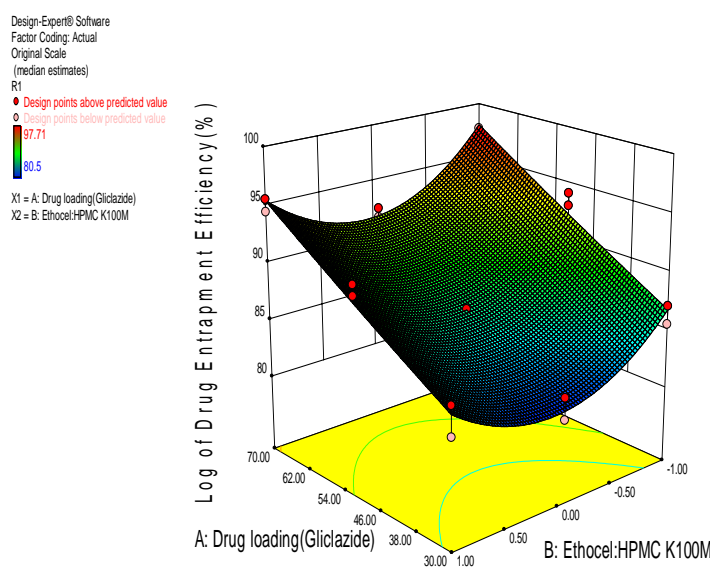

Figure 3. Response surface plot for drug entrapment efficiency for gliclazide microspheres prepared with Ethocel and HPMC K100M.

Table 8. Particle size distribution.
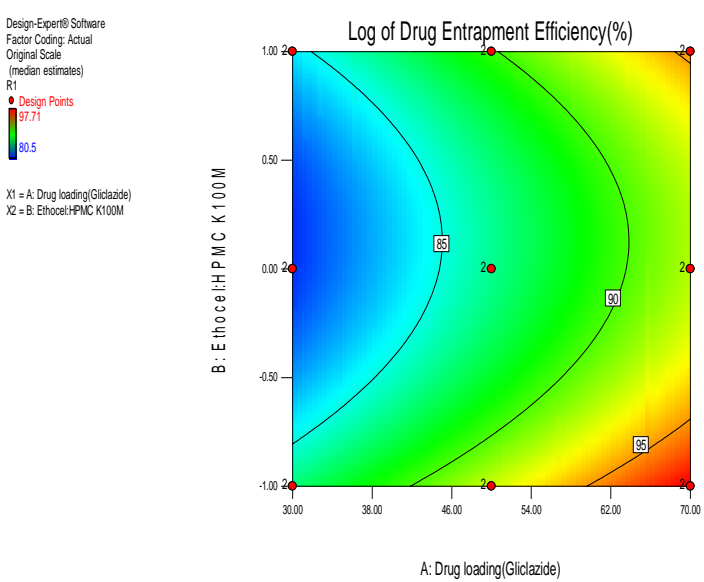

Figure 4. Contour plot for drug entrapment efficiency for gliclazide microspheres prepared with Ethocel and HPMC K100M.

\begin{tabular}{cccccc}
\hline Formulation & $\begin{array}{c}\text { Mean size } \\
(\mu \mathrm{m})\end{array}$ & $\begin{array}{c}\text { Median size } \\
(\mu \mathrm{m})\end{array}$ & $\begin{array}{c}\mathrm{D}(\mathrm{v}, 0.1) \\
(\mu \mathrm{m})\end{array}$ & $\begin{array}{c}\mathrm{D}(\mathrm{v}, 0.5) \\
(\mu \mathrm{m})\end{array}$ & $\begin{array}{c}\mathrm{D}(\mathrm{v}, 0.9) \\
(\mu \mathrm{m})\end{array}$ \\
\hline GC11 & 913.04 & 924.38 & 131.94 & 924.38 & 1487.09 \\
GC21 & 1430.00 & 1403.65 & 685.00 & 1403.65 & 2277.49 \\
GC31 & 1317.65 & 1246.24 & 607.58 & 1246.24 & 2182.10 \\
GC12 & 677.02 & 729.47 & 105.34 & 729.47 & 1086.29 \\
GC22 & 1393.36 & 1372.13 & 673.30 & 1372.13 & 2176.11 \\
GC32 & 1719.81 & 1700.45 & 1054.98 & 1700.45 & 2479.53 \\
GC13 & 472.23 & 254.24 & 113.05 & 254.24 & 1177.65 \\
GC23 & 1078.02 & 1041.64 & 314.24 & 1041.64 & 1835.81 \\
GC33 & 1321.39 & 1282.72 & 605.06 & 1282.72 & 2105.87 \\
\hline
\end{tabular}

Observation of particle morphology by scanning electron microscope (SEM). SEM study reveals that, microspheres prepared with HPMC K100LV have pores and cracks in the surface but the microsphere prepared in combination with Ethocel and HPMC K100M have no pores or cracks in their surface. Presence of pores or cracks may cause quick release since these facilitate the penetration of dissolution medium into the microsphere. Nature of the surface influences the stability and dissolution characteristics of the microspheres. If surface is rough, there are more chances of wetting and contact of water with the microsphere than the smoother one.
In vitro dissolution studies of gliclazide loaded polymeric microsphere.

Effect of polymer on release pattern of gliclazide microsphere. Microspheres of all the seventeen formulations were examined for dissolution pattern. GH3 showed better release retardant properties than the rest of the formulations prepared with HPMC K100LV alone. But, when Ethocel and HPMC K100M were used in combination, 3:1 ratio of Ethocel and HPMC K100M showed better release retardant properties. Ethocel and HPMC K100M when used in 1:3 ratios also exhibited release retardant properties which were better than 1:1 ratio of the two polymers. 
Successive fractional dissolution time. determined to characterize the drug release rate from Successive fractional dissolution times of seventeen the microspheres and the retaining efficiency of the formulations of gliclazide microsphere are discussed below. The $\mathrm{T}_{25 \%}, \mathrm{~T}_{50 \%}, \mathrm{~T}_{80 \%}$ and $\mathrm{MDT}$ values were polymers. Higher value of MDT indicates higher drug retaining ability of the polymer and vice-versa.

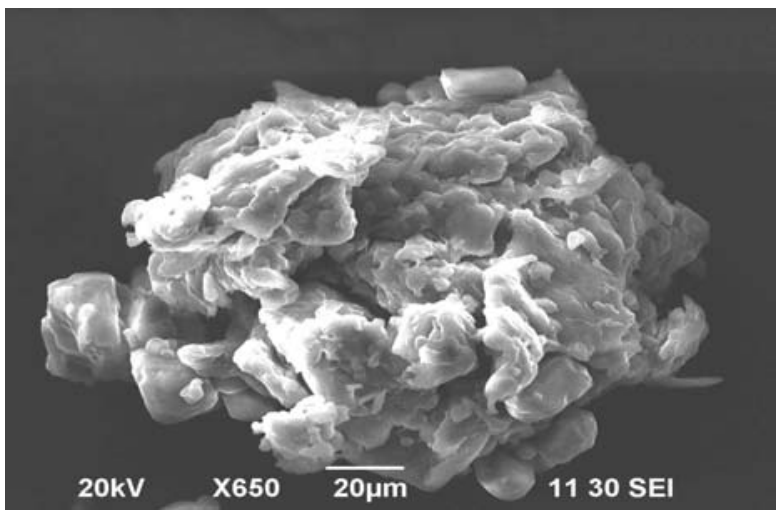

A

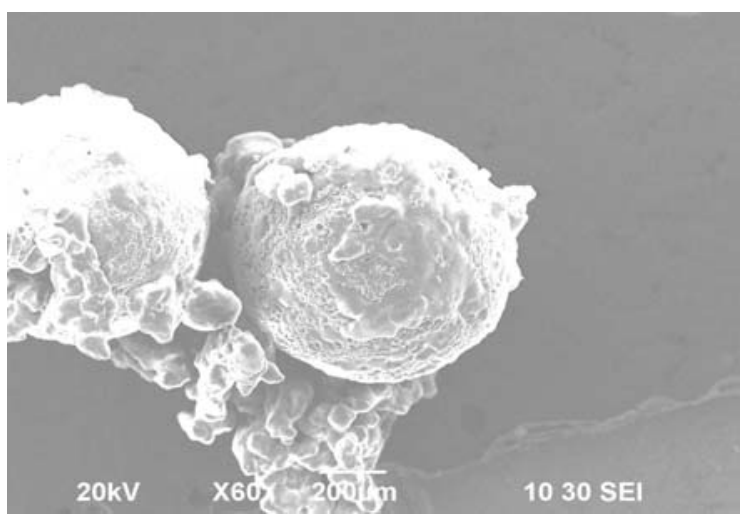

B

Figure 5. Scanning electron microscopic view of microspheres A. Formulation GH5 (Microspheres with HPMC K100LV), B. Formulation GC12 (Microspheres with Ethocel and HPMC K100M).

Table 9. Release rate constants and $\mathbf{R}^{2}$ values for different release kinetics for all batches of microspheres.

\begin{tabular}{|c|c|c|c|c|c|c|c|c|c|c|}
\hline \multirow[t]{2}{*}{ Formulation } & \multicolumn{2}{|c|}{ Zero order } & \multicolumn{2}{|c|}{ First order } & \multicolumn{2}{|c|}{ Higuchi } & \multicolumn{2}{|c|}{ Korsmeyer-Peppas } & \multicolumn{2}{|c|}{ Hixson Crowell } \\
\hline & $\mathrm{K}_{0}$ & $\mathrm{R}^{2}$ & $\mathrm{~K}_{1}$ & $\mathrm{R}^{2}$ & $\mathrm{~K}_{\mathrm{H}}$ & $\mathrm{R}^{2}$ & $\mathrm{~K}_{\mathrm{KP}}$ & $\mathrm{R}^{2}$ & $\mathrm{~K}_{\mathrm{HC}}$ & $\mathrm{R}^{2}$ \\
\hline GH1 & 11.93 & 0.963 & -0.421 & 0.922 & 35.29 & 0.987 & 0.244 & 0.985 & 0.183 & 0.981 \\
\hline $\mathrm{GH} 2$ & 7.846 & 0.622 & -0.309 & 0.936 & 27.9 & 0.837 & 0.388 & 0.985 & 0.179 & 0.959 \\
\hline GH3 & 6.53 & 0.9 & -0.106 & 0.963 & 21 & 0.991 & 0.259 & 0.985 & 0.093 & 0.947 \\
\hline GH4 & 9.169 & 0.839 & -0.228 & 0.973 & 30.35 & 0.977 & 0.366 & 0.977 & 0.187 & 0.942 \\
\hline GH5 & 9.61 & 0.835 & -0.292 & 0.979 & 31.85 & 0.975 & 0.416 & 0.977 & 0.237 & 0.958 \\
\hline GH6 & 10.57 & 0.89 & -0.451 & 0.873 & 34.24 & 0.992 & 0.394 & 0.988 & 0.327 & 0.966 \\
\hline GH7 & 8.144 & 0.835 & -0.203 & 0.945 & 26.58 & 0.947 & 0.433 & 0.918 & 0.201 & 0.933 \\
\hline GH8 & 8.406 & 0.86 & -0.173 & 0.959 & 27.44 & 0.975 & 0.293 & 0.932 & 0.193 & 0.937 \\
\hline GC11 & 6.378 & 0.939 & 0.097 & 0.98 & 19.04 & 0.994 & 0.202 & 0.988 & 0.087 & 0.97 \\
\hline GC21 & 7.003 & 0.95 & 0.108 & 0.982 & 21.92 & 0.99 & 0.176 & 0.996 & 0.097 & 0.976 \\
\hline GC31 & 4.408 & 0.908 & 0.058 & 0.942 & 14.14 & 0.994 & 0.324 & 0.99 & 0.054 & 0.932 \\
\hline GC12 & 3.677 & 0.883 & 0.046 & 0.922 & 11.87 & 0.979 & 0.162 & 0.975 & 0.053 & 0.911 \\
\hline $\mathrm{GC} 22$ & 5.942 & 0.946 & 0.085 & 0.98 & 18.69 & 0.995 & 0.151 & 0.998 & 0.092 & 0.971 \\
\hline GC32 & 4.471 & 0.88 & 0.058 & 0.919 & 14.51 & 0.987 & 0.149 & 0.986 & 0.065 & 0.907 \\
\hline GC13 & 6.246 & 0.875 & 0.088 & 0.896 & 19.96 & 0.951 & 0.132 & 0.965 & 0.108 & 0.891 \\
\hline GC23 & 5.191 & 0.634 & 0.08 & 0.697 & 18.53 & 0.859 & 0.316 & 0.882 & 0.095 & 0.677 \\
\hline GC33 & 4.312 & 0.911 & 0.055 & 0.942 & 13.79 & 0.992 & 0.127 & 0.986 & 0.069 & 0.932 \\
\hline
\end{tabular}



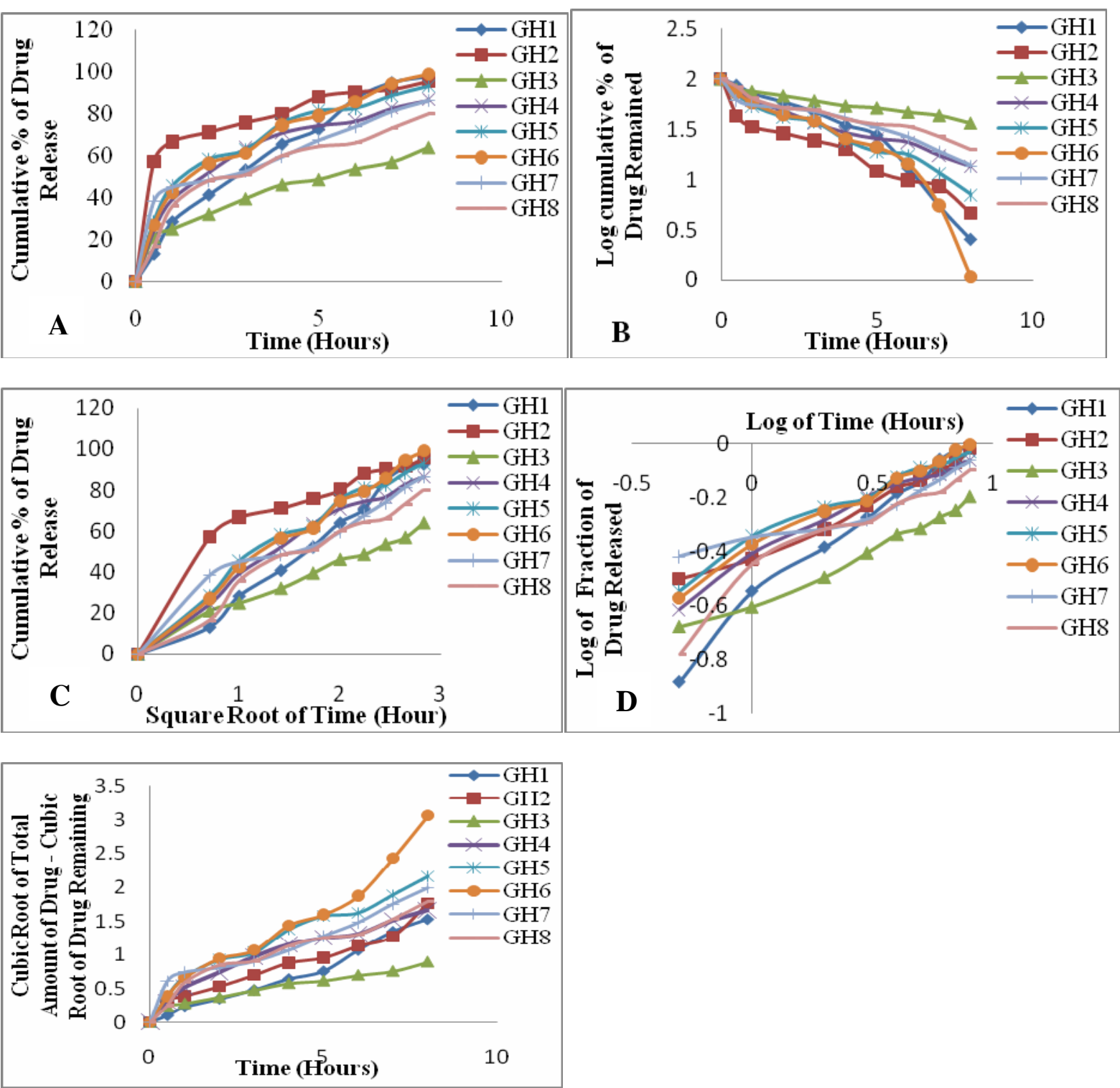

$\mathbf{E}$

Figure 6. In vitro release kinetics of gliclazide microspheres prepared with HPMC K100LV A. Zero order plot, B. First order plot, C. Higuchi plot, D. Korsmeyer-Peppas plot, E. Hixson-Crowell plot. 


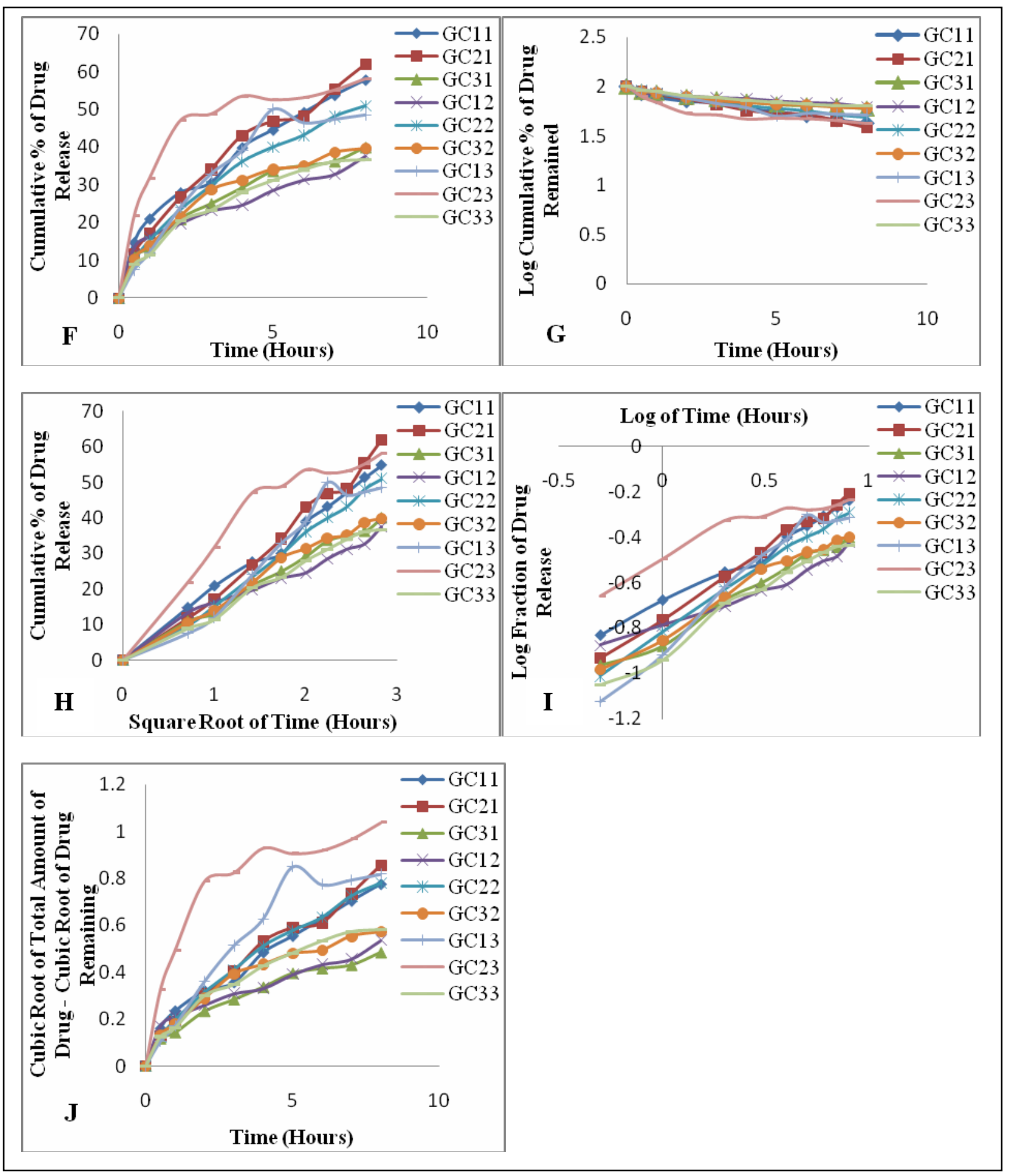

Figure 7. In vitro release kinetics of gliclazide microspheres prepared with Ethocel and HPMC K100M F. Zero order plot, G. First order plot, H. Higuchi plot, I. Korsmeyer-Peppas plot, J, Hixson-Crowell plot. 
Table 10. Best fitted model and mechanism of drug release from polymeric microspheres.

\begin{tabular}{clcl}
\hline Formulation & Best fitted model & $\mathrm{n}$ value & Release mechanism \\
\hline GH1 & Higuchi & 0.698 & Non-Fickian/Anomalous transport \\
GH2 & KorsmeyerPeppas & 0.403 & Fickian transport \\
GH3 & Higuchi & 0.403 & Fickian transport \\
GH4 & Higuchi and Korsmeyer- & 0.438 & Fickian transport \\
GH5 & Peppas & 0.400 & Fickian transport \\
GH6 & First order & 0.447 & Fickian transport \\
GH7 & Higuchi & 0.285 & Fickian transport \\
GH8 & Higuchi & 0.497 & Non-Fickian/Anomalous transport \\
GC11 & Higuchi & 0.487 & Non-Fickian/Anomalous transport \\
GC21 & Korsmeyer-Peppas & 0.597 & Non-Fickian/Anomalous transport \\
GC31 & Higuchi & 0.489 & Non-Fickian/Anomalous transport \\
GC12 & Higuchi & 0.359 & Fickian transport \\
GC22 & Korsmeyer-Peppas & 0.598 & Non-Fickian/Anomalous transport \\
GC32 & Higuchi & 0.501 & Non-Fickian/Anomalous transport \\
GC13 & Higuchi & 0.717 & Non-Fickian/Anomalous transport \\
GC23 & Korsmeyer-Peppas & 0.316 & Fickian transport \\
GC33 & Higuchi & 0.544 & Non-Fickian/Anomalous transport \\
\hline
\end{tabular}

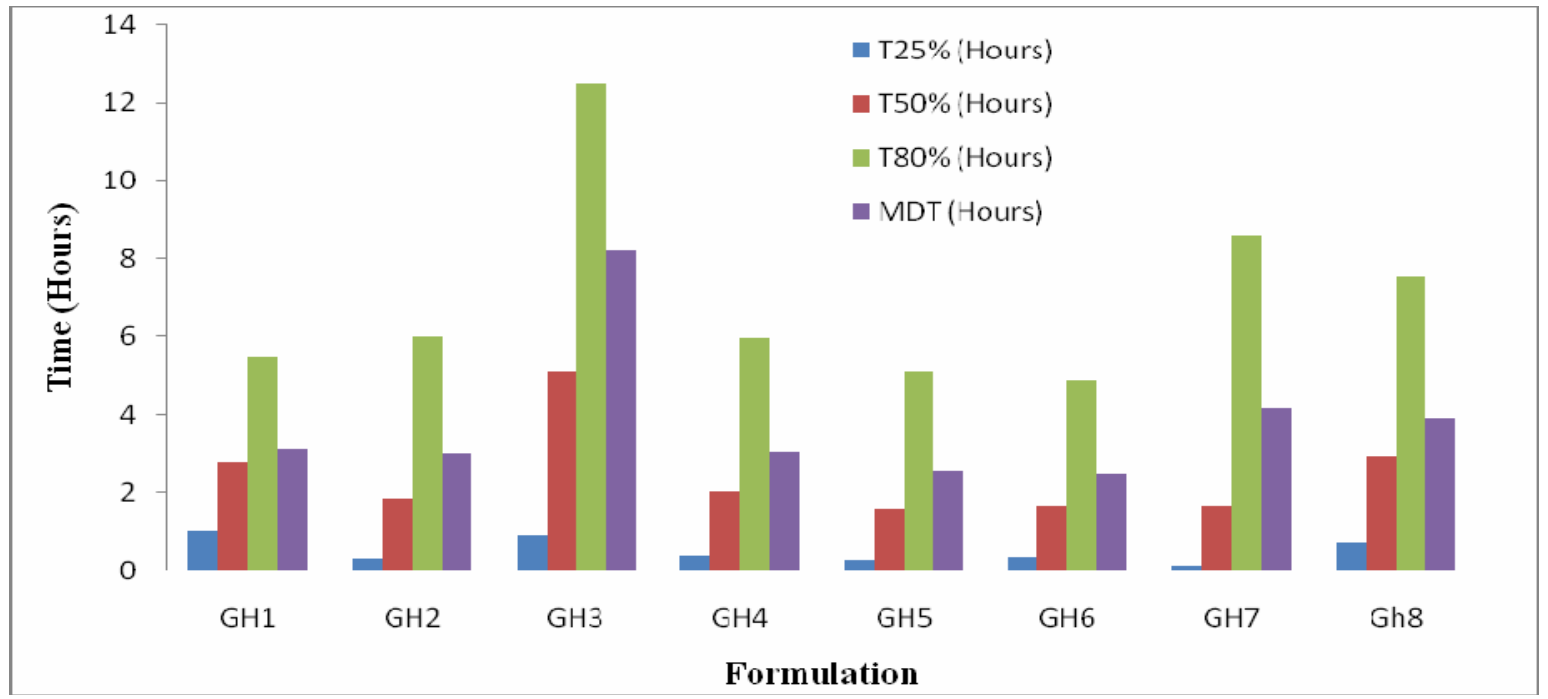

Figure 8. Bar diagram representing successive fractional dissolution time of GH1, GH2, GH3, GH4, GH5, GH6, GH7 and GH8. 


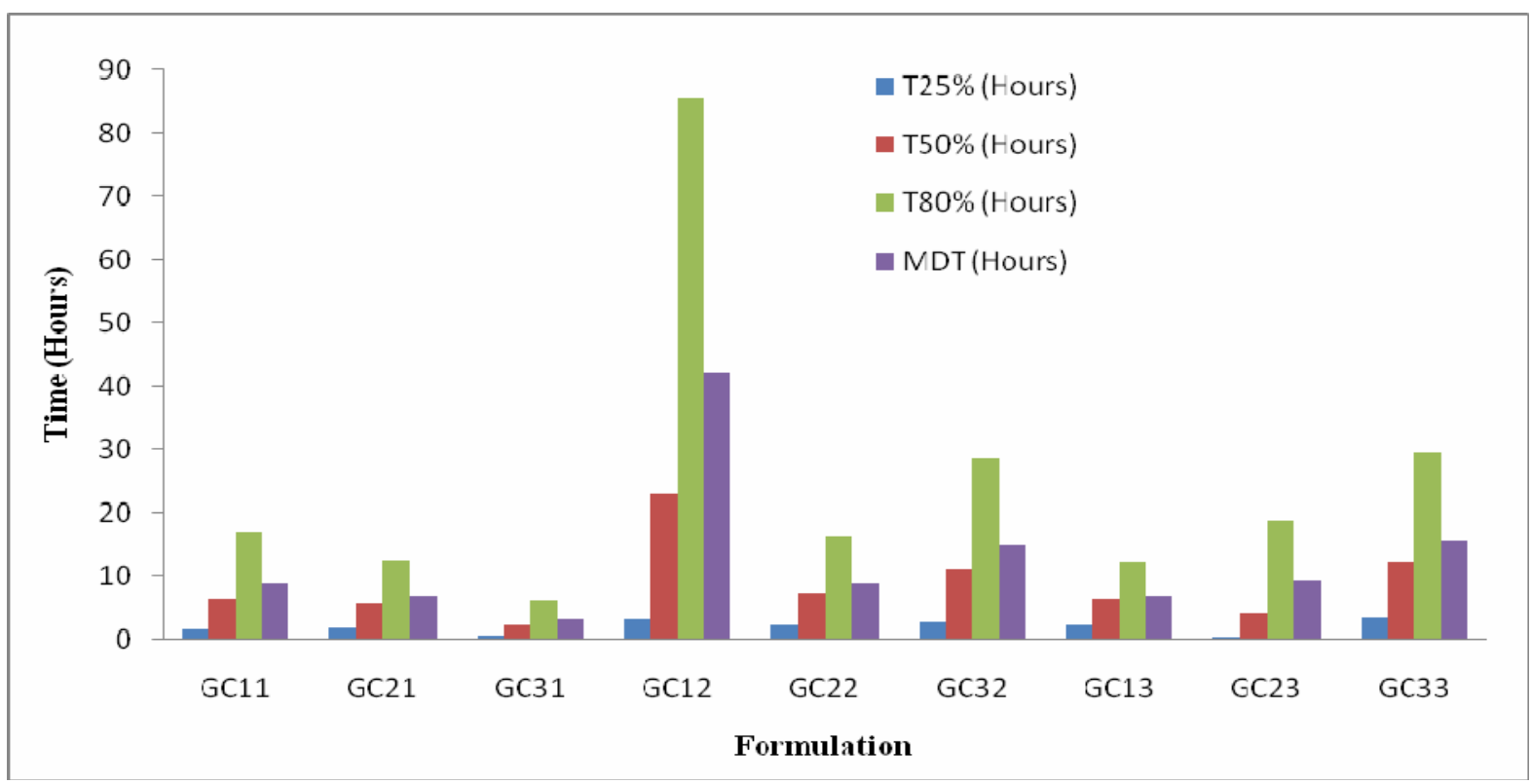

Figure 9. Bar diagram representing successive fractional dissolution time of GC11, GC21, GC31, GC12, GC22, GC32, GC13, GC23 and GC33.

Analysis of impact of drug loading and polymer on successive fractional dissolution time. Successive fractional dissolution times were analyzed by gg plot software (R i386.3.0.0).

Table 11. Codes for different variables for construction of complex line-plot by gg plot to analyze impact of drug loading and polymer ratio on successive fractional dissolution time.

\begin{tabular}{lc}
\hline Parameter & Code \\
\hline Presence of a polymer & 1 \\
Absence of a polymer & 0 \\
Single polymer & $\mathrm{a}$ \\
Combination of polymer $(1: 3)$ & $\mathrm{b}$ \\
Combination of polymer $(1: 1)$ & $\mathrm{c}$ \\
Combination of polymer $(3: 1)$ & $\mathrm{d}$ \\
HPMC K100LV & 1 \\
Ethocel+HPMC K100M & 2 \\
\hline
\end{tabular}

Compatibility studies of drug and polymer within gliclazide microspheres.

Fourier transform infrared spectroscopy (FTIR) study: Fourier transform infrared spectroscopic (FTIR) study was conducted for the pure drug (Gliclazide), sample GH5 (Gliclazide microsphere containing HPMC K100LV) and sample GC23 (Gliclazide microsphere containing mixture of Ethocel and HPMC K100M).
Figure 11 represents the FTIR spectrum of pure gliclazide. Many peaks are visible in this spectrum but the most prominent bands are-

1. Secondary amine N-H stretching at $3275.19 \mathrm{~cm}^{-1}$ and bending at $1597.09 \mathrm{~cm}^{-1}$.

2. $=\mathrm{CH}$ stretching at $3113.16 \mathrm{~cm}^{-1}$.

3. Acyclic ketone carbonyl $(\mathrm{C}=\mathrm{O})$ stretching at $1709.92 \mathrm{~cm}^{-1}$.

4. $\mathrm{SO}_{2} \mathrm{NH}$ stretching at $1354.05 \mathrm{~cm}^{-1}$.

5. Sulphonyl $\mathrm{S}=\mathrm{O}$ stretching at $1164.06 \mathrm{~cm}^{-1}$.

Here, secondary amine $(\mathrm{N}-\mathrm{H})$ possesses one band for stretching at $3275.19 \mathrm{~cm}^{-1}$ and one band for bending at $1597.09 \mathrm{~cm}^{-1}$. Rest of the four prominent functional groups of gliclazide possesses one peak for stretching. Figure 12 represents spectrum of GH5, which is a batch of microspheres prepared by using HPMC K100LV. Now if this spectrum is compared with the spectrum of gliclazide, then it is found that peaks for $\mathrm{N}-\mathrm{H}$ stretching and bending, $=\mathrm{CH}$ stretching, carbonyl $\mathrm{C}=\mathrm{O}$ stretching, $\quad \mathrm{SO}_{2} \mathrm{NH}$ stretching and sulphonyl $\mathrm{S}=\mathrm{O}$ stretching all are present here at $3272.29 \mathrm{~cm}^{-1}, 1597.09 \mathrm{~cm}^{-1}, 3113.16$ $\mathrm{cm}^{-1}, 1710.89 \mathrm{~cm}^{-1}, 1354.05 \mathrm{~cm}^{-1}$ and $1164.06 \mathrm{~cm}^{-1}$ respectively which indicate the presence of these 
groups, in other words those are indication of no interaction.

Figure 13 represents spectrum of GC23, which is a batch of microsphere prepared with Ethocel and HPMC K100M. Now, if this spectrum is compared with the spectrum of Gliclazide, then it is found that peaks for N-H stretching and bending, $=\mathrm{CH}$ stretching, carbonyl $\mathrm{C}=\mathrm{O}$ stretching, $\quad \mathrm{SO}_{2} \mathrm{NH}$ stretching and sulphonyl $\mathrm{S}=\mathrm{O}$ stretching all are present here at $3274.22 \mathrm{~cm}^{-1}, 1597.09 \mathrm{~cm}^{-1}, 3114.13$
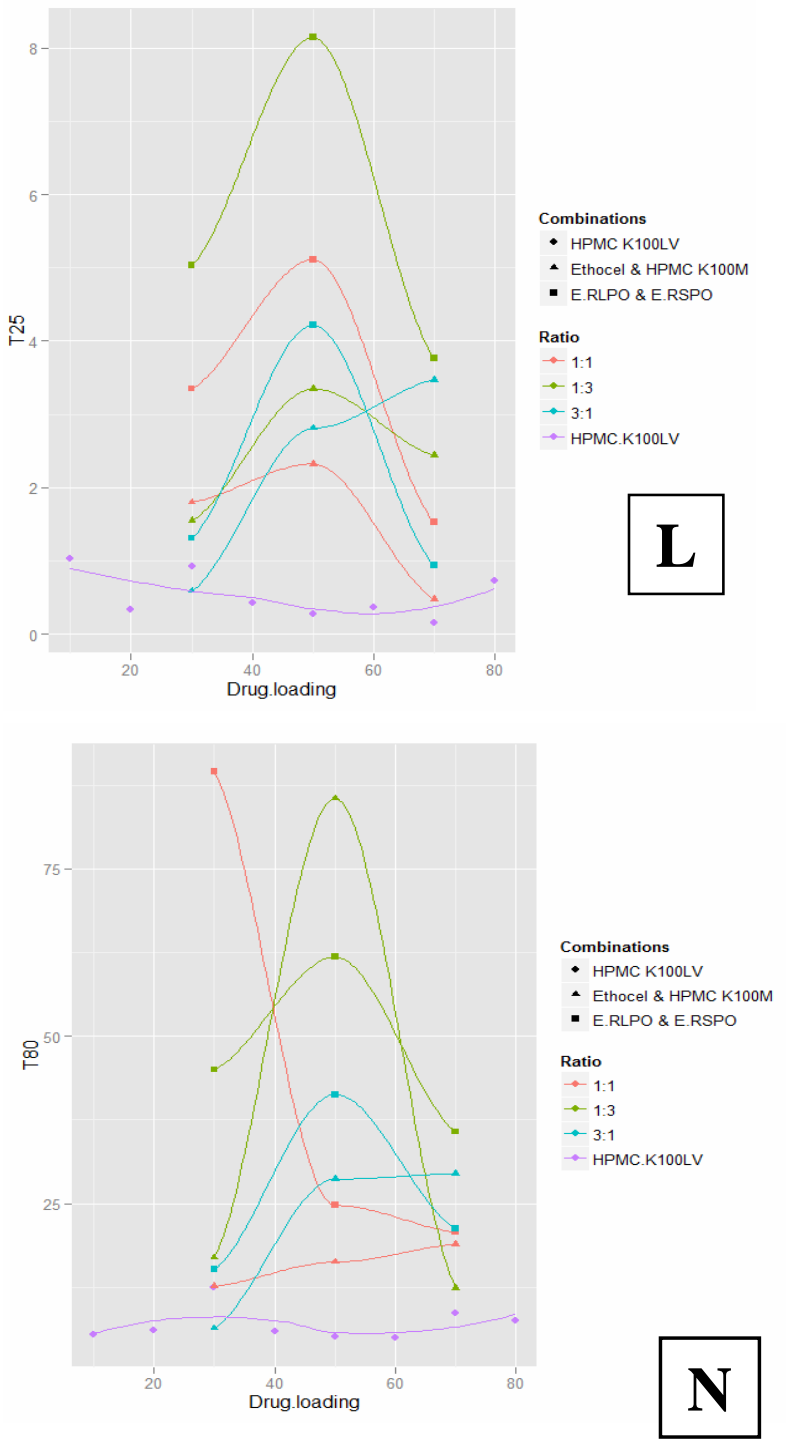

$\mathrm{cm}^{-1}, 1709.92 \mathrm{~cm}^{-1}, 1357.30 \mathrm{~cm}^{-1}$ and $1164.06 \mathrm{~cm}^{-1}$ respectively which are indication of the presence of these groups. This also reveals the absence of any interaction.

Differential scanning calorimetric (DSC) study. The data obtained from all of these samples are viewed here as combined thermogram of drug, polymers and microspheres prepared with Ethocel and HPMC K100LM.
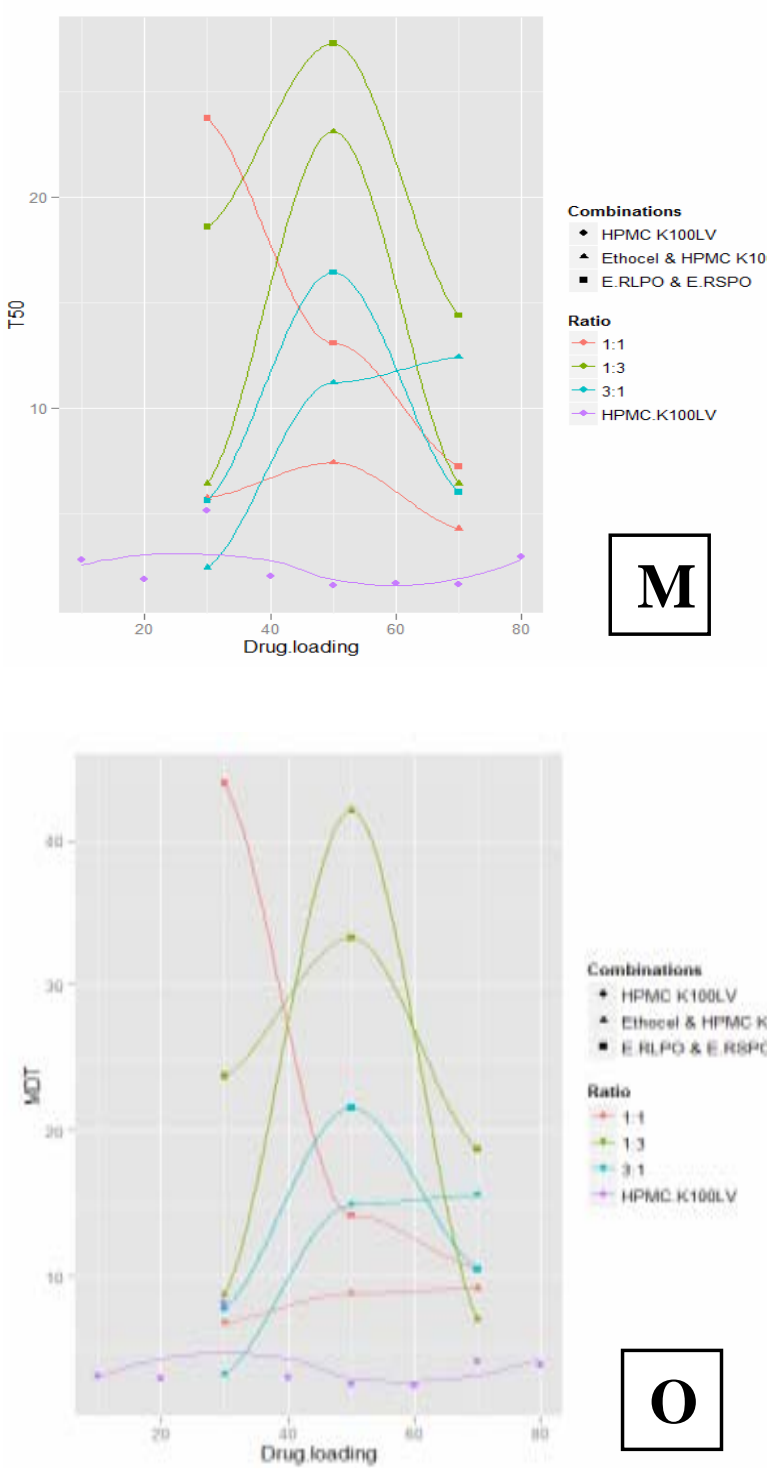

Figure 10. Complex line-plot: L. T $25 \%$; M. $\mathrm{T}_{50 \%} ; \mathrm{N} . \mathrm{T}_{80 \%} ; \mathrm{O}$. MDT. 


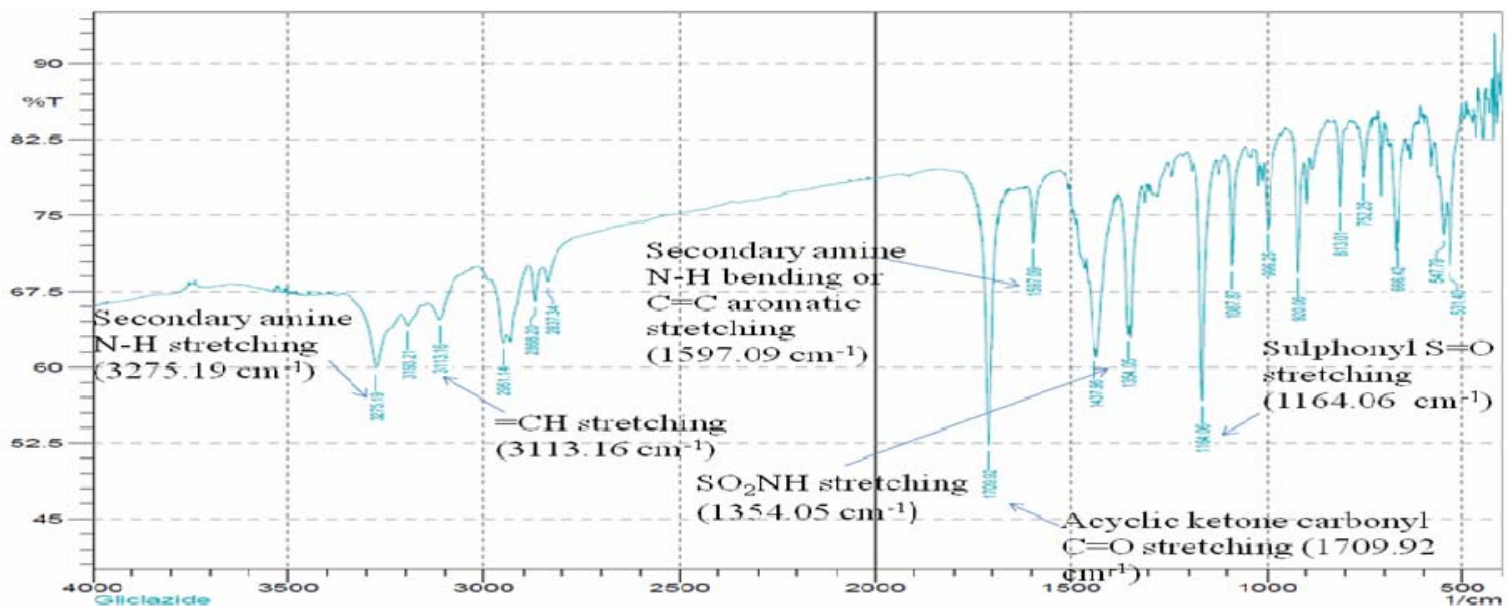

Figure 11. FTIR spectrum of pure gliclazide.

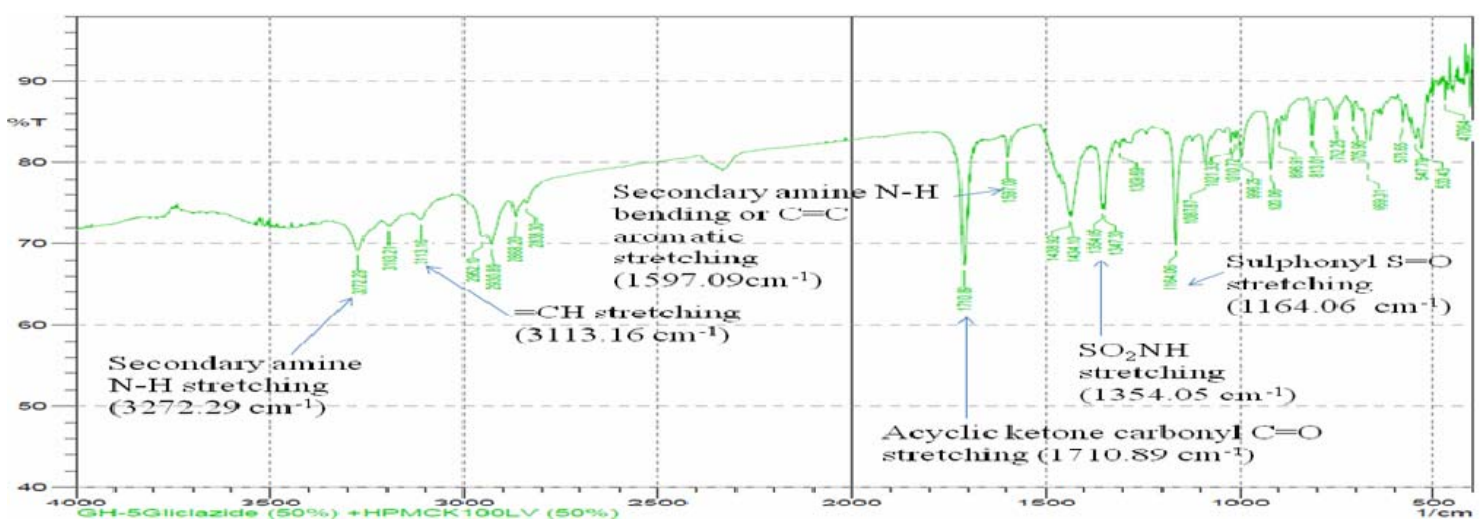

Figure 12. FTIR spectrum of GH5 (gliclazide microsphere prepared with HPMC K100LV).

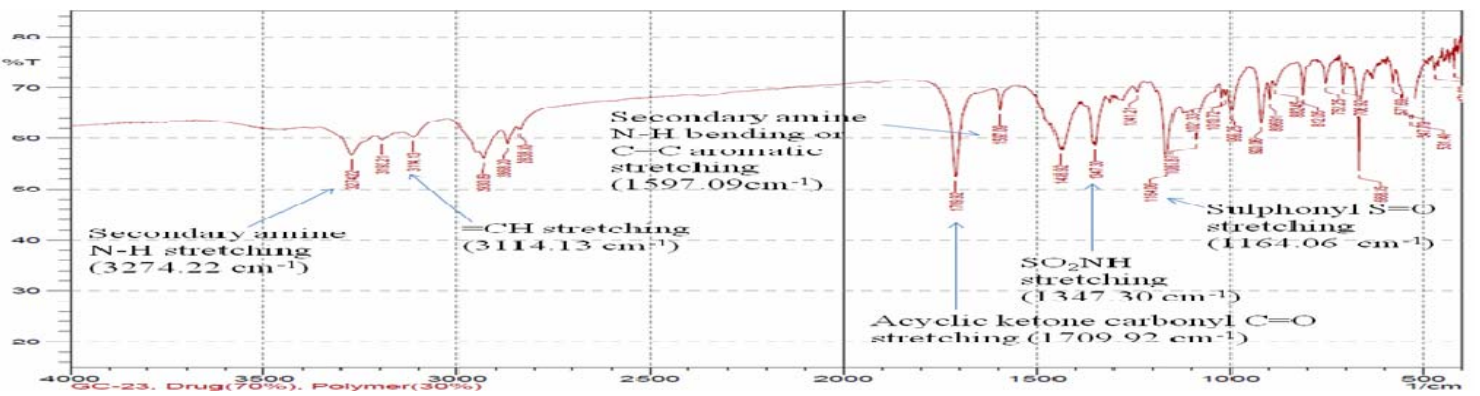

Figure 13. FTIR spectrum of GC23 (gliclazide microsphere prepared with HPMC K100LM and Ethocel). 


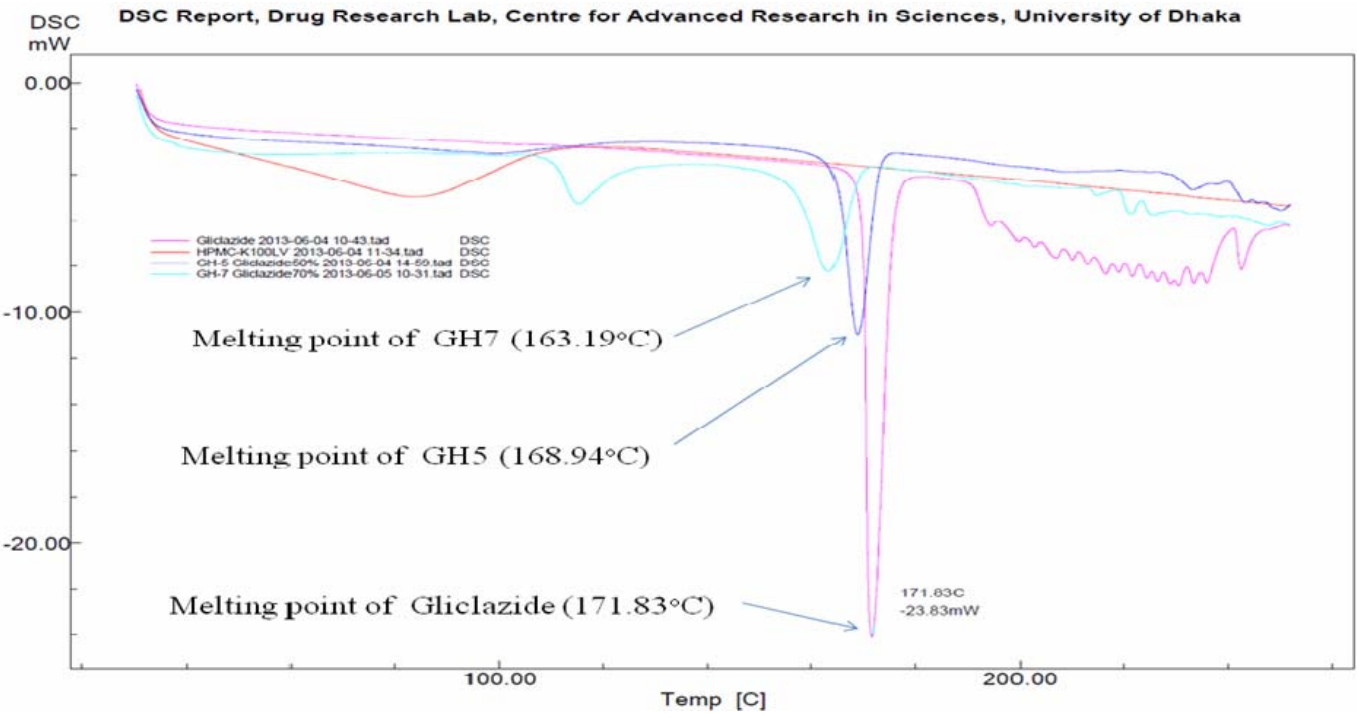

Figure 14. Combined DSC thermogram of pure gliclazide, HPMC K1000LV and two batches of microspheres of gliclazide prepared with HPMC K100LV.

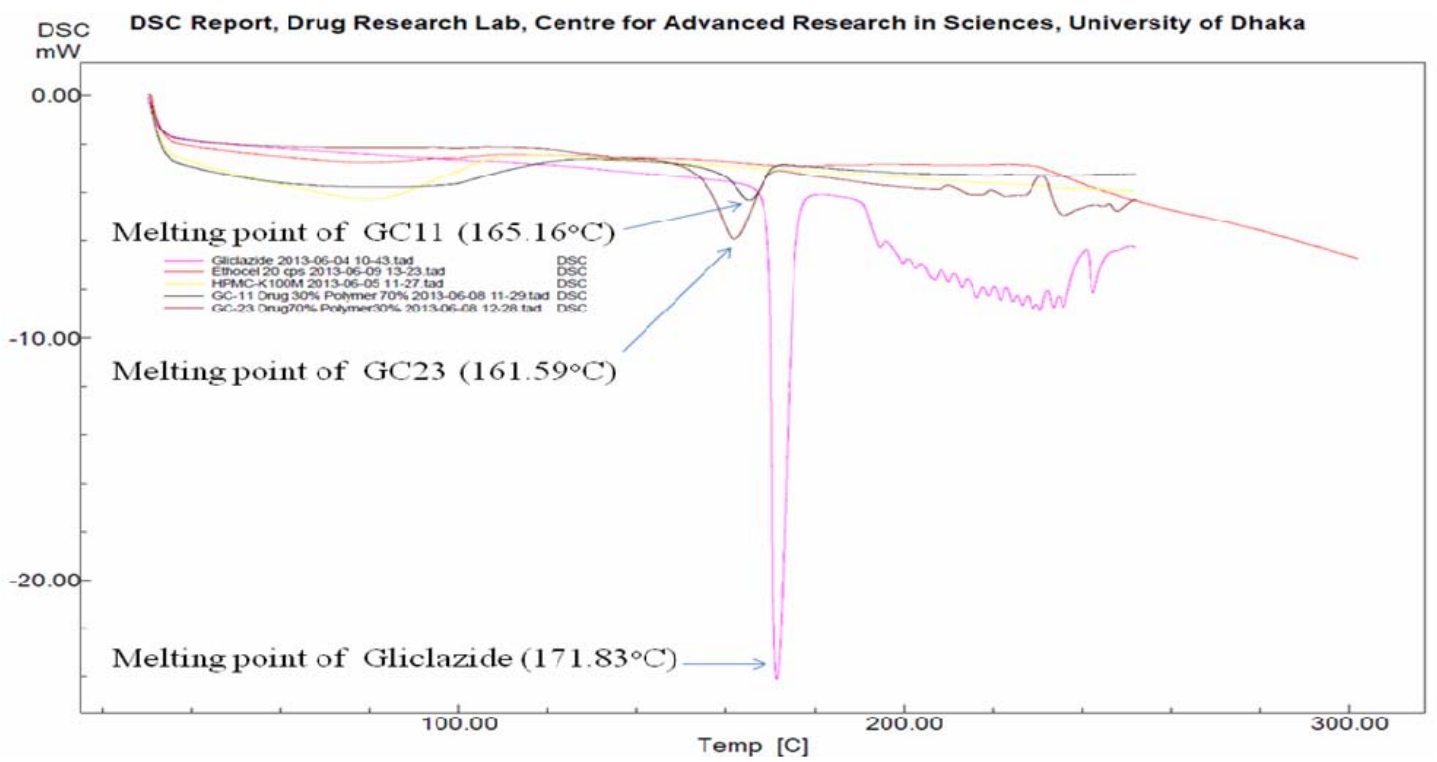

Figure 15. Combined DSC thermogram of pure gliclazide, HPMC K100M, Ethocel and two batches of microspheres of gliclazide prepared with HPMC K100M and Ethocel.

No drastic change occurred to the melting point of the microspheres in comparison with pure gliclazide in case of the microspheres prepared with HPMC K100LV alone or microspheres prepared with Ethocel and HPMC K100M in combination. So it can be said that there is no interaction between drug (gliclazide) and the polymers (HPMC K100LV, HPMC K100M and Ethocel).

\section{CONCLUSION}

In this study, polymeric microspheres of gliclazide were prepared successfully by emulsification-solvent evaporation technique. Microspheres prepared with a combination of Ethocel and HPMC K100M were proved to be of good quality compared to the microspheres prepared with HPMC K100LV alone, as all the microspheres from 
former batches possessed spherical like shape and the particle size of most of the batches were within the acceptable size range $(1-1000 \mu \mathrm{m})$.

Various variables like drug loading, polymeric type and polymer ratio (in case microspheres prepared by using mixture of polymers) all have direct effect on different characteristics of the microsphere.

Microspheres prepared with only HPMC $\mathrm{K} 100 \mathrm{LV}$, though have better entrapment efficiency, but cannot retard the release of the drug for a prolonged period. But when Ethocel is blended with HPMC K100M a more sustained release of the drug is obtained. Drug loading also influences entrapment efficiency as well as release rate. The entrapment efficiency increases with increase in drug loading for the microspheres prepared with Ethocel and HPMC K100M. Among three different ratios used (1:3, 1:1 and 3:1), 1:3 ratio of Ethocel and HPMC K100M showed better sustained release properties. Other parameters like surface morphology or particle size are also influenced by drug loading, polymeric property or by the ratio of two polymers.

To optimize the various properties of microspheres by using polymers of different permeability characteristics, a $3^{2}$ factorial design was investigated taking drug loading and polymeric ratio as the independent variables and the various properties of the microspheres like entrapment efficiency, release rate as the dependent variables. This however, opened a newer approach to formulate micro particulate dosage form of optimum in vitro characteristics by manipulating drug loading and changing polymeric ratio.

\section{REFERENCES}

1. Gunjan, A., Sharma, N., Gupta, M., Khinchi, M.P., Verma, R. and Mishra, S.S. 2012. A review of microencapsulation as novel drug delivery. Asian J. Pharma. Edu. Res. 1, 53-66.

2. Bakan, J.A. 1986. Microencapsulation. In: The Theory and Practice of Industrial Pharmacy (Lachman, L., Lieberman, H. A., Kanig, J. L., Febiger, L., Eds.), Philadelphia, pp. 412429.
3. Sahil, K., Akanksha, M., Premjeet, S., Bilandi, A. and Kapoor, B. 2011. Microshperes: A Review. Int. J. Res. Pharma. Chem. 1, 1184-1198.

4. Sarker, A., Tiwari, A., Bhasin, P.S. and Mitra, M. 2011. Pharmacological and pharmaceutical profile of gliclazide: a review. J. Appl. Pharma. Sci. 1, 11-19.

5. Colombo, P. 1993. Swelling-controlled release in hydrogel matrices for oral route. Adv. Drug Deliv. Rev. 11, 37-57.

6. Doelker, E. 1986. Water-swollen cellulose derivatives in pharmacy. Hydrogels in Medicine and Pharmacy. CRC Press, Boca Raton, pp. 115-160.

7. Peppas, L.B. 1990. Preparation and characterization of crosslinked hydrophilic networks. In: Absorbent Polymer Technology, Elsevier, Amsterdam, pp. 45-66.

8. Peppas, L.B. and Peppas, N.A. 1990. The equilibrium swelling behavior of porous and non-porous hydrogels. In: Absorbent Polymer Technology, Elsevier, Amsterdam, pp. 67-102.

9. Odonnell, P.B. and McGinity, J.W. 1997. Preparation of microspheres by the solvent evaporation technique. Adv. Drug. Deli. Rev. 28, 25-42.

10. Gonjari, I.D., Karmarkar, A.B., Khade, T.S., Hosmani, A.H. and Navale, R.B. 2010. Use of factorial design in formulation and evaluation of ophthalmic gels of gatifloxacin: comparison of different mucoadhesive polymers. Drug. Dis. Thera. 4, 423-434.

11. Hooda, A., Nanda, A., Jain, M., Jumara, V. and Rathee, P. 2012. Optimization and evaluation of gastroretentive ranitidine $\mathrm{HCl}$ microspheres by using design expert software. Int. J. Bio. Macrmol. 51, 691-700.

12. Senthil, A., Hardik, R.T., Ravikumar and Narayanswamy, V.B. 2011. Chitosan loaded mucoadhesive microspheres of gliclazide: in vitro and in vivo evaluation. J. Phar. Sci. 1, 163-171.

13. United States Pharmacopoeia, XXIX, The United States Pharmacopoeial Convention Inc. 2006.

14. Lumay, G., Boschini, F., Traina, K., Bontemp, S., Remy, J.C., Cloots, R. and Vandewalle, N. 2012. Measuring the flowing $\mathrm{n}$ - properties of powders and grains. In: Powder Technol. 224, 19-27.

15. Sunitha, S., Amareshwar, P. and Kumar, M.S. 2010. A Study on the Effect of Different Cellulose Polymers on Release Rate from Tramadol Loaded Microspheres Prepared by Emulsion Solvent Evaporation Method. Asian J. Phar. Clin. Res. 3, 35-39.

16. Hasan, I., Paul, S., Akhter, S., Ayon, N.J. and Reza, M.S. 2013. Evaluation and optimization of influence of permeability property and concentration of polymethacrylic polymers on microspheres of metformin $\mathrm{HCl}$. Dhaka Univ. J. Pharm. Sci. 12, 131-141. 
17. Chung, T.W., Huang, Y.Y. and Liu, Y.Z. 2001. Effects of the rate of solvent evaporation on the characteristics of drug loaded PLLA and PDLLA microspheres. Int. J. Pharm. 212, 161-169.

18. Izumikawa, S.S., Yoshioka, Y. and Takeda, Y. 1990. Preparation of poly (I-lactide) microspheres of different crystalline morphology and effect of crystalline morphology on drug release rate. J. Cont. Rel. 15, 133- 140.
19. Peppas, N.A. 1985. Analysis of Fickain and non-Fickian drug release from polymers. Pharm. Acta Helv. 60, 110-112.

20. Costa, P. and Lobo, J.M.S. 2001. Modeling and comparison of dissolution profiles, European J. Phar. Sci. 13, 123-133.

21. Balpande, H.M., Raut, N.S., Umekar, M.J. and Kotagale, N.R. 2013. Compatibility study of metformin with pharmaceutical excipients. Int. J. Chem. Tech. Res. 5, 16841693. 